
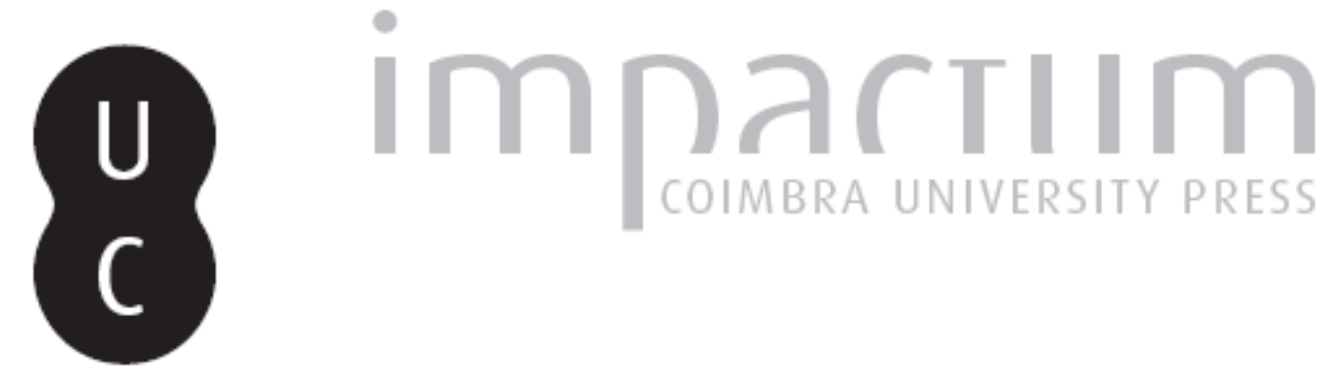

\title{
Marchena, 'anarquista': liberalismo exaltado y jacobinismo en el trienio liberal
}

Autor(es): $\quad$ Francisco Fuentes, Juan

Publicado por: Imprensa da Universidade de Coimbra

URL persistente:

URl:http://hdl.handle.net/10316.2/43776

DOI:

DOI:https://doi.org/10.14195/2183-8925_10_17

Accessed : $\quad$ 26-Apr-2023 08:20:53

A navegação consulta e descarregamento dos títulos inseridos nas Bibliotecas Digitais UC Digitalis, UC Pombalina e UC Impactum, pressupõem a aceitação plena e sem reservas dos Termos e Condições de Uso destas Bibliotecas Digitais, disponíveis em https://digitalis.uc.pt/pt-pt/termos.

Conforme exposto nos referidos Termos e Condições de Uso, o descarregamento de títulos de acesso restrito requer uma licença válida de autorização devendo o utilizador aceder ao(s) documento(s) a partir de um endereço de IP da instituição detentora da supramencionada licença.

Ao utilizador é apenas permitido o descarregamento para uso pessoal, pelo que o emprego do(s) título(s) descarregado(s) para outro fim, designadamente comercial, carece de autorização do respetivo autor ou editor da obra.

Na medida em que todas as obras da UC Digitalis se encontram protegidas pelo Código do Direito de Autor e Direitos Conexos e demais legislação aplicável, toda a cópia, parcial ou total, deste documento, nos casos em que é legalmente admitida, deverá conter ou fazer-se acompanhar por este aviso.

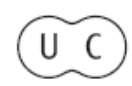


REVISTA DE HISTORIA DAS IDEIAS IO
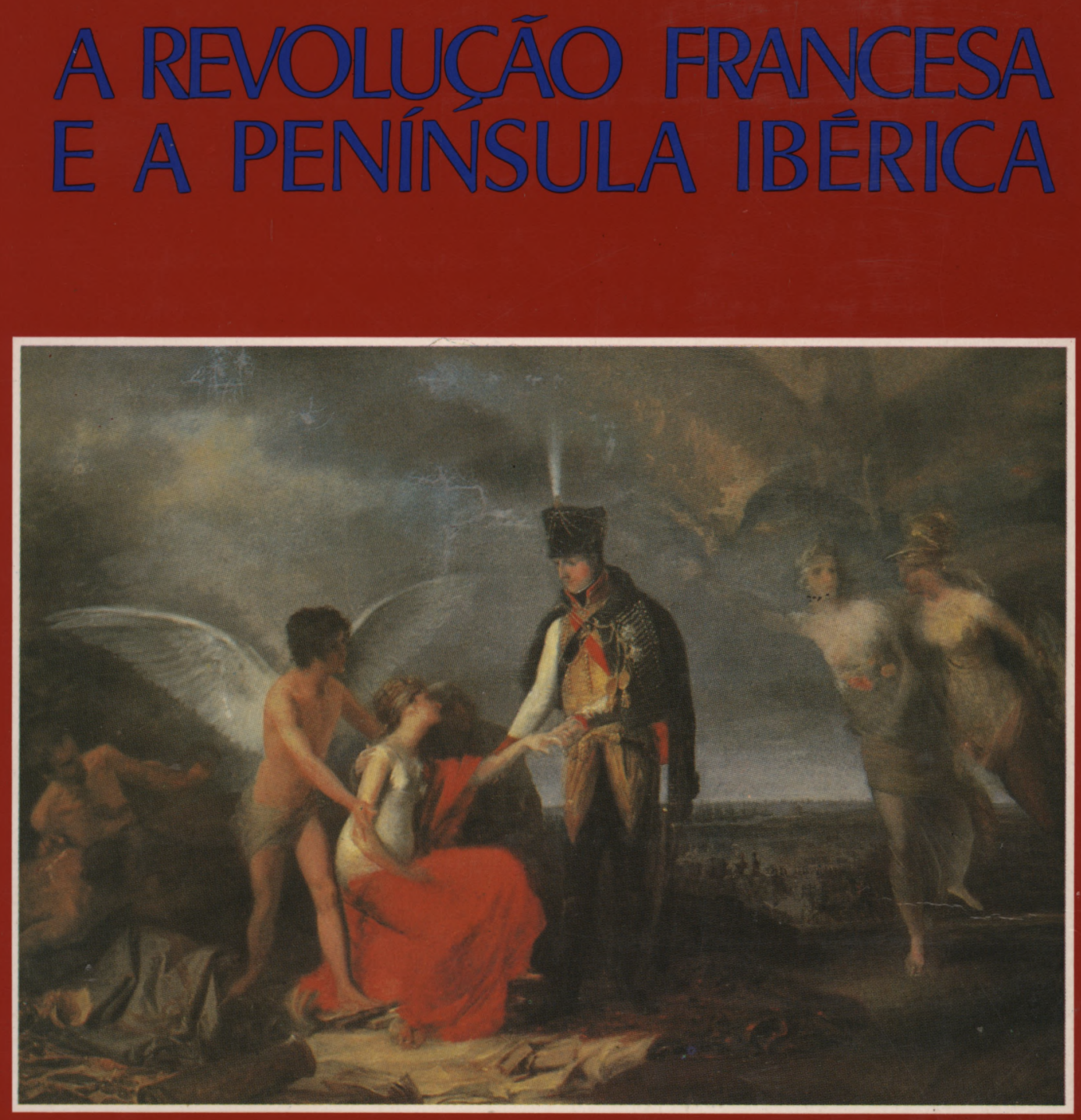

INSTITUTO DE HISTÖRIA E TEORIA DAS IDEIAS FACULDADE DE LETRAS 
JUAN FRANCISCO FUENTES *

\section{MARCHENA, 'ANARQUISTA' LIBERALISMO EXALTADO Y JACOBINISMO EN EL TRIENIO LIBERAL}

Como un jacobino apasionado define a José Marchena don Pedro Sáinz Rodríguez $\left(^{1}\right)$, recogiendo una imagen estereotipada del personaje divulgada por la historiografía tradicional y que arranca de Menéndez Pelayo, su principal biógrafo $\left({ }^{2}\right)$. Sus relaciones con el partido girondino el año $93 \mathrm{y}$ la persecución experimentada en la época del Terror bastan para desautorizar el tópico sobre la filiación jacobina de Marchena durante su estancia en la Francia revolucionaria. Pero el papel que desempeñó en los primeros meses del Trienio liberal podría prestarse a confusión. Su alineamiento, a finales de 1820 , con el sector exaltado del liberalismo español le valió en la época el dicterio de anarquista, es decir, de jacobino. En un texto que se comentará más adelante, no muy anterior a su muerte, Marchena rechaza esa imputación recordando su ejecutoria personal, y especialmente los dieciséis meses de cautiverio «en los calabozos del jacobinismo» $\left({ }^{3}\right)$. Por razones obvias,

* Universidad Complutense de Madrid.

(1) Pedro Sáinz Rodríguez, "Las antiguas antologías y la historia literaria", Libro Homenaje a Antonio Pérez Gómez, Cieza, 1978, II, p. 160.

(2) Marcelino Menéndez Pelayo, El Abate Marchena, Buenos Aires, Espasa-Calpe, 1946.

(3) Copia de la carta dirigida al Exmo. Sr. D. Juan O'Donojú, capitán general de la provincia de Sevilla, gefe político de la misma, teniente general de los reales egércitos, edecán de S.M., gran cruz de las órdenes de Carlos III y de san Hermenegildo \& \& \& por el abate Marchena, publicada por el Diario Gaditano, n. ${ }^{\circ} 98,21$ de diciembre de 1820, reeditada por Alberto Gil Novales, Textos exaltados del Trienio liberal, Madrid-Gijón, Eds. Júcar, 1979, y por Fernando Díaz Plaja en las Obras en prosa de Marchena, Madrid, Alianza Ed., 1985. En realidad parece que fueron catorce los meses pasados por Marchena en la cárcel de la Conciergerie. 
omite un argumento tan contundente como su colaboración con la Monarquía de José I.

Sentado el hecho de que Marchena no fue nunca jacobino, parece útil interrogarse sobre las razones que le llevaron a militar en el liberalismo exaltado, en gesto verdaderamente insólito entre los josefincs. Creo que el análisis de sus escritos postreros permitirá explicar esta aparente anomalía en su trayectoria política.

Es sabido que, restablecida la Constitución en marzo de 1820, el regreso de los exiliados josefinos se demoró todavía unos meses. Su enorme impopularidad fue la causa de que el primer gobierno liberal se mostrara reacio a la concesión del perdón y acabara transfiriendo el problema a las Cortes. Hubo una generosa propuesta del diputado Moreno Guerra presentada a la Cámara en el mes de julio, pero no fue hasta finales de septiembre cuando, en medio de una fuerte polémica, las Cortes autorizaron la repatriación de los afrancesados. Entre ellos se encontraba don José Marchena, antiguo funcionario del Ministerio del Interior con el rey José, si bien su digno comportamiento en el exilio y su contribución al restablecimiento de las libertades ( ${ }^{4}$ ) le distinguían notablemente del común de sus correligionarios. De Montpellier, su última residencia en Francia, se trasladó a su Sevilla natal, adonde llegó probablemente en octubre de 1820. Le quedaban sólo cuatro meses de vida, y sin embargo, ese breve tramo final de su existencia iba a resultar enormemente agitado y fecundo.

Tres son, que se sepa, los textos publicados por Marchena en aquellos últimos meses de 1820: el Discurso sobre la ley relativa a extinción de monacales y reforma de regulares $\left(^{5}\right)$, pronunciado en la sociedad patriótica de Sevilla, que poste-

(4) Aparte su labor en la difusión de la literatura ilustrada en España, consta que, a partir de 1814, Marchena unió sus esfuerzos a los de los exiliados liberales en la lucha contra la Monarquía absoluta (cfr. el artículo de Georges Demerson "Marchena à Perpignan», Bulletin Hispanique, LIX, 1957, pp. 284-303). Creo que la adhesión de Marchena en esa época a la Constitución liberal y su combatividad política en el exilio anuncian ya lo que será su comportamiento político del Trienio, tan distinto del de sus antiguos compañeros en la burocracia josefina. Como «acusados que piden perdón o tratan de justificarse» definió magistralmente a los afrancesados Vicente Lloréns (Liberales y románticos, Madrid, Ed. Castalia, 1979, p. 211).

(5) Discurso sobre la ley relativa a extinción de monacales $y$ reforma de regulares, pronunciado en el día 6 de Noviembre del presente año en la Sociedad Patriótica constitucional de esta ciudad por cl ciudadano $D$. Josef Marchena, socio intimo de la misma, e impreso por aclamación general, Sevilla. Imprenta de Caro, 1820. Texto reeditado por Fernando Díaz Plaja, ob. cit. 
riormente costeó su impresión; la carta al capitán general don Juan O’Donojú $\left({ }^{6}\right)$, publicada por el Diario Gaditano, y una exposición a la comisión permanente de las Cortes, leída en la propia sociedad patriótica e impresa asimismo en el Diario Gaditano $\left({ }^{7}\right)$. Los tres guardan relación con la actividad de Marchena en el seno de la sociedad patriótica de Sevilla, de la que fue nombrado socio honorario a propuesta de un conocido militante exaltado: el negociante gaditano don Juan MacCrohon. Con ser muy diversa su temática y los hechos a que hacen referencia, estos textos reflejan una común preocupación por el desarrollo democrático de la Constitución de Cádiz y el fortalecimiento del régimen liberal, muy en la línea del ideario de los llamados exaltados $\left(^{8}\right)$.

El primero de estos impresos, la defensa de la ley relativa a las órdenes religiosas, admite, en mi opinión, tres distintos niveles de lectura: uno metafísico-doctrinal, otro político y, finalmente, un plano social. En aquellos pasajes del discurso que atañen al cuerpo dogmático del catolicismo, el autor no consigue disimular por completo sus inclinaciones deístas, si bien elude, mediante el recurso a ciertos eufemismos, una confrontación directa con la sensibilidad religiosa del auditorio. Tal. el empleo de la fórmula religión divina para evocar unas creencias a todas luces heterodoxas sin impugnar expresamente la validez del catolicismo. O la atribución a Cristo, formulada como mera hipótesis. de una sola naturaleza, poniendo veladamente en entredicho la unión hipostática. O la expresión gran Demiurgos que utiliza para designar a la Divindad. Pero, más allá de estas escaramuzas teológicas, Marchena plantea una cuestión doctrinal con importantes derivaciones políticas, y es el derecho de la religión católica para exigir un reconocimiento exclusivo por la sociedad, y, por otra parte, la con-

(6) Cfr. supra, n. 1.

(7) A la comisión permanente de las Cortes, los ciudadanos españoles habitantes de Sevilla que abajo firman, exposición reproducida en el Diario Gaditano el 3 de enero de 1821, acompañada de una carta de Marchena al autor del periódico, ciudadano Clararrosa, en la que asume la autoría del documento. Lo reproduce Alberto Gil Novales en Las sociedades patrióticas, Madrid, Tecnos, 1975, p. $454 \mathrm{n}$.

(8) La actitud ante la Constitucón - recelosa y revisionista en los moderados, expansiva y leal en los exaltados - es la línea divisoria que separa a los dos grandes sectores del liberalismo español en el Trienio. Por exaltados, según Gil Novales, hay que entender "no meramente a los liberales partidarios de la Constitución de Cádiz, sino a los que no se conforman con la sola música del articulado, y quieren llevar a la práctica, a la realidad, las promesas constitucionales» (A. Gil Novales, Textos exaltados, ob. cit., p. 12). 
veniencia de que el Estado consagre la unidad de culto, tal como hacía la Constitución española en su artículo 12. La verdad es que el autor no llega a pronunciarse sobre la bondad $\mathrm{d} \epsilon$ este precepto constitucional, aunque,, en un largo pasaje de su discurso, recuerda que "los más de los filósofos y estadistas» consideran que estas cuestiones deben ser ajenas al quehacer del legislador, que «los más ilustres teólogos» han defendido la libertad de conciencia frente a todo tipo de coacción, y en definitiva, que el contrato social no puede regular las convicciones religiosas del ciudadano, por lo mismo que no puede obligarle a reconocer un determinado principio científico, como el de las moléculas orgánicas o el del ovario. Añade, finalmente, que, según los tratadistas más solventes, las leyes coactivas son no sólo injustas con el hombre, sino también injuriosas con el Ser Supremo, pues «lo que a los hombres infunde la fe no son las instituciones sociales, sino la divina gracia, que no de este precepto constitucional, aunque, en un largo pasaje de dispensa Dios al antojo de los legisladores» $\left({ }^{9}\right)$. Marchena hace como que se mantiene al margen de esta discusión - «nosotros, afirma, prescindiremos de todos estos argumentos» -, pero, como dice un contemporáneo, «no queda duda en que reprueba que el artículo de Constitución haga Religión del Estado la católica» $\left({ }^{10}\right)$. De su oposición a la unidad religiosa, expresada aqui, con cierto pudor, había dejado constancia en un texto redactado unos meses antes, en el que anunciaba la publicación de una obra suya titulada De la tolerancia religiosa.

«En ella - decía Marchena - expondremos los medios más acertados para allanar el camino que ha de conducir a la libertad de cultos, sin excitar disturbios en la plebe, y especialmente para templar, en cuanto fuera dable, los males que acarrea necesariamente al Estado un culto que se ha declarado nacional» (11).

(9) Discurso sobre la ley..., ob. cit., p. 9.

(10) L.V.C., Discurso o impugnación católica y piadosa de algunas proposiciones del discurso que sobre la extinción de monacales y reforma de regulares, hizo el 6 de Noviembre anterior en la Sociedad patriótica constitucional de esta Ciudad el Abate, Ciudadano D. José Marchena, socio intimo que se titula de ella, y consejos útiles que en ella le da un amigo, Sevilla, Imprenta de Caro Hernández, 1820, p. 16.

(11) Nota del traductor a la obra De la libertad religiosa. Traducido del francés del señor A.V. Benoît, por don Josef Marchena, Barcelona, sin fecha. Hay una edición, probablemente algo anterior, de Mompeller (sic), 1820. 
Es claro, pues, que Marchena considera pernicioso el famoso artículo 12 sobre la unidad religiosa, lo cual le coloca en la vanguardia del liberalismo español, pero, hombre pragmático, reconoce que el arraigo que la religión católica tiene en el pueblo aconseja prudencia en la lucha por la libertad religiosa ${ }^{(2)}$. De ahí el recurso al eufemismo y al circunloquio en el texto que comento.

Pues bien, dada esa realidad social, legitimada por el artículo 12 de la Constitución, lo que procede, según nuestro autor, es exigir a la Iglesia católica que corresponda a ese trato privilegiado con su sometimiento a las instituciones liberales:

"Grandes son los derechos que la ley constitucional ha conferido a los ministros de la religión católica, empero por eso mismo no son menores las obligaciones a que los ha sujetado. Ni pudiera ser menos, pues derecho $\mathrm{v}$ obligación son palabras relativas, y no es posible adquirir un derecho legítimo, sin contraer una obligación» (13).

Y la primera obligación, añade,

"es no reconocer otros superiores que los que le señale el gobierno, los cuales han de ser aquellos que más abonadas fianzas ofrezcan de que son sus principios de moral social los que a la potestad civil convinieren» (14).

En la argumentación de Marchena hay un habilidoso ejercicio de prestidigitación política: se trata de convertir uno de los preceptos más regresivos de la Constitución en un arma contra las tentaciones liberticidas de la Iglesia. Tal es, en definitiva. la principal inquietud del autor del discurso: la defensa de las libertades, que es también la gran obsesión del liberalismo exaltado. Por eso lamenta el autor que la ley promulgada por las Cortes para la reforma de las órdenes religiosas no llegue a afectar a determinados monasterios, que de esta forma «podrán muy bien - dice Marchena - convertirse en armerías, donde se fragüen armas para dar batería al régimen constitucional».

Si tras el análisis del contenido doctrinal y político de este texto prestamos atención a su vertiente social, nos sorprende la falta de interés del autor por la suerte de esas pro-

(12) Es obvio que no comparto la opinión de Fernando Díaz Plaja respecto al discurso sobre la reforma de las órdenes religiosas, en el sentido de que «al comentar el decreto sobre los bienes de monacales Marchena habló como lo hubiera hecho en Francia» (F. Díaz Plaja, ob. cit., p. 215 n.).

(13) Discurso sobre la ley, ob. cit., p. 13.

(14) Ibidem, p. 14. 
priedades que la ley de órdenes religiosas pone en manos del Estado. Ciertamente, no se le ocultan las ventajas que va a reportar la movilización de riquezas hasta entonces hurtadas a la nación $\left({ }^{15}\right)$. Pero el autor no llega a plantearse en ningún momento los diferentes destinos que el Estado podía dar a las propiedades desamortizadas, por ejemplo, facilitar el acceso a ellas del pequeño y mediano campesinado y ensanchar así la base social del régimen. Es claro que esa alternativa jacobina al Antiguo Régimen no podía ser asumida por un hombre como Marchena, por mucho que sus enemigos políticos y algunos de sus biógrafos le hayan imputado, contra toda evidencia, inclinaciones jacobinas. Por lo demás, son varios los autores que han señalado la escasa sensibilidad social del liberalismo exaltado, especialmente ante la cuestión agraria, como una seria objeción para su homologación con el jacobinismo francés $\left({ }^{16}\right)$.

La polémica levantada por este discurso terminó con una purga política en el seno de la sociedad patriótica sevillana, controlada por elementos moderados, que consiguieron la expulsión de don José Marchena a los pccos días de su ingreso en la corporación. En este contexto escribió nuestro autor su célebre carta al capitán general O’Donojú, responsable en la sombra de la campaña de difamación emprendida contra el general Riego, y ulteriormente contra el propio Marchena.

La carta a O'Donojú es uno de sus textos más mordaces, más finos $\mathrm{y}$, afortunadamente, más conocidos. Yo no voy a entrar a ponderar su grandeza literaria ni el valor casi testamentario que tienen las últimas líneas de este opúsculo. Aquí interesa sobre todo como exponente de una cierta concepción del liberalismo, que repudia el moderantismo de las autoridades liberales tanto como la tradición jacobina. Hay en el texto alguna pincelada de doctrina política - como la defensa del derecho de crítica a la labor del magistrado - y sobre todo

(15) «¿A quién se pueden esconder los perjuicios que a España redundaban del estanco de inmensas fincas en manos muertas, la posesión de abundantísimas riquezas en premio de la ociosidad, o de faenas totalmente inútiles para el cuerpo social, tantos capitales sacados de la circulación, enterrados en lo interior de los santuarios, como si el oro y la plata fuesen más preciosos a la vista del que lo crió todo que el barro y la arcilla, como si tuviera el Eterno ojos de carne, y valuara los objetos por el aprecio que en virtud de sus necesidades y facultades hacen de ellos los flacos mortales?» (Discurso sobre la ley...., ob. cit., pp. 4-5).

(16) Cfr., por ejemplo, el libro de Josep Fontana, La crisis del Antiguo Régimen, 1808-1833, Barcelona, Crítica, 1979, cap. "Las divisiones internas del liberalismo", y el artículo, todavía inédito, de la prof. Nadiezdha Cosores ¿Por qué no hubo jacobinos ien el Trienio? 
una toma de posición ante ciertos temas de actualidad, como hábían sido la campaña contra Riego, la disolución del ejército de la Isla y el papel nada honorable que el general O'Donojú había representado en todo ello. La persecución contra Riego $\mathrm{y}$ otros militares liberales era un elemento verdaderamente central del debate político del momento, una especie de piedra de toque que permitía situar a unos y a otros en el panorama político del Trienio. El Héroe de las Cabezas de San Juan representaba con su ejemplo un determinado estilo en la defensa de la libertad: energía, audacia, generosidad personal, todo ello opuesto al oportunismo y a la versatilidad de personajes como el propio O'Donojú. Estos dos militares polarizaban, como digo, el liberalismo español en un sector radical, que asume la figura de Riego como símbolo mismo de la Revolución, y un sector moderado que, aun a riesgo de desarmar política y moralmente al régimen, se afana por aplacar el espíritu democrático que anima a amplios sectores de opinión. Marchena denuncia el papel del general O'Donojú en la ejecución del trabajo sucio del gobierno en la persecución a los militares liberales, a la vez que recuerda, no sin cierta malicia, la pasividad de O'Donojú en los momentos críticos del alzamiento liberal.

«Ello es cierto que es triste cosa no haber tenido parte en la restauración de la libertad de la patria, quien en aquella época hubiera podido decidir oportunamente la contienda con sólo declararse. Mas también hemos de atender a que el papel de expectante, si no es el más glorioso, por lo menos es el más seguro, ya que la prudencia persuade a abstenerse de coger laureles que pueden ir envueltos en cipreses» (17).

Los celos podrían muy bien ser la razón de la saña con que el capitán general de Sevilla ha procedido contra Riego y sus compañeros, pero la campaña dirigida desde la capitanía general contra el autor de la carta, origen de su expulsión de la sociedad patriótica sevillana, tiene más difícil explicación. Porque,

«en conciencia, Sr. Excmo., ¿quién se ha de persuadir a que soy yo un enemigo de la libertad, cuando tantas persecuciones he sufrido por su causa, un hombre que anda pidiendo cabezas de majaderos, un anarquista cuando por espacio de diez $\mathrm{v}$ seis meses en mi primera juventud me vi encerrado en los calabozos del jacobinismo?" (18).

(17) Cito el texto según la edición de A. Gil Novales, Textos exaltados, ob. cit., p. 96.

(18) Ibidem, p. 97. 
Marchena termina su carta manifestando su convencimiento de que la amenaza jacobina no justifica la renuncia a los grandes ideales del liberalismo:

«Nunca los excesos del populacho me harán olvidar los imprescriptibles derechos del pueblo; siempre sabré arrostrar la prepotencia de los magnates, lidiando por la libertad de mi patria» (19).

El mismo periódico que publicó la carta a O’Donojú, el Diario Gaditano de Clararrosa, publicó unos días después una exposición suya a la comisión permanente de las Cortes pidiendo la convocatoria de Cortes extraordinarias, especie de Convención a la francesa, al decir de Menéndez Pelayo $\left({ }^{20}\right)$. Es un documento redactado antes que la carta al capitán general de Sevilla, aunque, como digo, fuera publicado posteriormente. Se trata de hecho, por su fecha de publicación, de su último texto impreso.

La exposición a la comisión permanente recoge todos los grandes temas del liberalismo exaltado: la persecución contra Riego y otros oficiales liberales, la inquietante ambigüedad del monarca, la impunidad de los liberticidas, la culpable debilidad del gobierno moderado y el acoso al régimen por parte de sus enemigos interiores y exteriores - «enemigos, dice premonitoriamente Marchena, opulentos, numerosos y encarnizados» La insensibilidad del poder al clamor popular no impedirá, según el autor, el triunfo final de la libertad, pero quién sabe si para ello no recurrirá el pueblo a lo que Marchena llama el «espantable auxilio» de la anarquía. Estamos, pues, ante uma nueva muestra de ese discurso ambiguamente democrático nunca jacobino - que caracteriza al liberalismo de nuestro personaje y, en general, al movimiento exaltado, y que consiste en utilizar al pueblo como argumento extremo en la defensa y en el desarrollo de la Constitución. Algo más adelante, el autor expone con gran elocuencia su concepción de la libertad, en lo que constituye el morceau de bravoure de esta proclama:

"La libertad es una matrona austera que, desnuda de arreos, como la verdad, en su propia desnudez vincula su decencian.

Es el testimonio de un gran escritor y de un viejo revolucionario, pero sobre todo creo que la frase nos brinda la ocasión de adentrarnos hasta lo más profundo del pensamiento político del autor.

(19) Ibidem.

(20) El Abate Marchena, ob. cit., p. 129. 
Estas palabras ocupan en el texto un lugar privilegiado: cerrando un párrafo y después de un período largo y farragoso, que contribuye a resaltar la concisión y rotundidad de esta declaración. Esa sonora contundencia de la frase contrasta, además, con el estilo melifluo que, a juicio del autor, caracteriza a los representantes de la Nación en sus discusiones parlamentarias y que es, a su entender, la expresión retórica de su escasa energía en la defensa de la Constitución. Pero la cita suscita sobre todo una reflexión en torno al concepto mismo de libertad, que obliga a una reconsideración de la experiencia histórica posterior a 1789. Excuso recordar el valor emblemático que la Libertad tiene en esa fecha para la burguesía y para el propio pensamiento liberal. Es sabido, asimismo, que a partir de 1793 el régimen del Terror llevará las consignas de 1789 más allá del marco formal que les había asignado el liberalismo burgués, de suerte que la etapa terrcrista alterará profundamente el sentido $\mathrm{y}$ el alcance de los valores fundacionales de la Revolución liberal. La aportación jacobina marca, pues, como un estigma histórico, los conceptos de Libertad e Igualdad, por lo que, a partir del año II, el liberalismo se siente forzado a una reelaboración y a una redefinición de sus valores genéricos. En el orden semántico, se trata de desactivar la carga subversiva que el Terror ha incorporado a la voz Libertad, de ahí que en la literatura liberal la vieja consigna revolucionaria aparezca cautiva, secuestrada por adjetivos que la envilecen: se habla de una libertad templada, de libertad bien entendida, de libertad sabia, de libertad y orden, de libertad razonable. $\mathrm{O}$ bien se la convierte en un vago atributo moral de la persona, carente de todo significado político. La libertad, dice por ejemplo Guizot,

"c'est le droit de notre nature divine refusant de se soumettre à notre nature terrestre réclamant le Dieu dont elle émane pour ne s'humilier que devant lui» (21).

Es la labor que lleva a cabo también Jeremías Bentham en su obra Anarchical fallacies, que ejercerá una notable influencia en la configuración de un liberalismo moderado en España ${ }^{(22}$ ). Así, en un artículo publicado en marzo de 1821, titu-

(21) F. Guizot, Philosophie politique, cap. XX (cit. por Luis Díaz del Corral, El liberalismo doctrinario, Centro de Estudios Constitucionales, Madrid, 1984, pp. 234-235).

(22) Cfr. al respecto el excelente artículo de Antonio Elorza «La icieología moderada en el Trienio liberal», Cuadernos Hispanoamericanos, junio de 1974, pp. 584-650. Cfr. también la obra de L. Díaz del Corral, citada en la nota anterior. 
lado «Origen del liberalismo europeo», el periódico madrileño El Censor meditaba sobre el riesgo democrático que desde la Revolución francesa entrañaba la doctrina liberal:

«Sólo hay un peligro para el liberalismo - dice el órgano afrancesado - , y es su degeneración. Mientras proteja las garantías y los intereses sociales, nada tiene que temer; mas si degenera en licencia, el instinto de la sociedad la obligará a arrojarse hacia la parte opuesta y a sacrificar algunos intereses para conservar la existencia. Esta es la terrible lección que nos ha dado la revolución de Francia» (23).

La actuación de los gobiernos moderados del Trienio se halla fuertemente influida por la nueva sensibilidad histórica de la burguesía, por ese liberalismo revisionista que preconiza El Censor. En el caso español, se añadía además la debilidad objetiva de la burguesía nacional, que accedió a renunciar a una parte de su programa democrático en aras de un entendimiento con la aristocracia y la corona. Pues bien, la frase de Marchena no es otra cosa que la réplica a esa revisión a la baja del programa liberal. La voz Libertad debe, según él, conservar su integridad de sustantivo, mantenerse, pues, libre de epítetos - «desnuda de arreos», dice él - que la maticen o la degraden. Es decir, tal como en 1789.

En sus Retratos políticos de la Revolución española, Carlos Lebrun afirma que, a su vuelta a España en 1820, Marchena fue perseguido por querer «libertad monda y lironda» $\left({ }^{24}\right)$. Creo que no se puede definir con mayor exactitud y donosura el compromiso político que orienta el comportamiento de nuestro personaje en aquellos últimos meses de vida: su aportación a un desarrollo democrático de la Constitución gaditana, su clamor por una defensa enérgica de las libertades y sobre todo su fe en la plena vigencia de la utopía libertaria que impulsó la Gran Revolución. Ello bastó para que un josefino y antigua víctima del Terror como él fuera admitido en las filas del liberalismo exaltado. Al fin y al cabo, tal como ha señalado la profesora Cosores, para hombres como Romero Alpuente, como MacCrohon, como los periodistas exaltados, «la cuestión era

(23) Cit. por Elorza, ob. cit., p. 601.

(24) Carlos Lebrun, Retratos políticos de la Revolución de España, o de los principales personajes que han jugado en ella, muchos de los cuales están sacados en caricaturas por el ridículo en que ellos mismos se habian puesto, cuando el retratista los iba sacando; con unas observaciones políticas al fin sobre la misma; y la resolución de la cuestión de por qué se malogró ésta, y no la de los Estados Unidos. Impreso en Filadelfia, año 1826, p. 317. 
cómo defender más efectivamente a la revolución por medios políticos, militares y administrativos» $\left({ }^{25}\right)$. Es precisamente en ese terreno, tan alejado de todo jacobinismo, donde se produce el encuentro entre nuestro hombre y el movimiento exaltado. Que ese encuentro fuera posible se explica por las carencias políticas del liberalismo radical español, pero también por la fidelidad de Marchena a las consignas revolucionarias del año 89.

(25) Art. cit. supra, n. 16. 